\title{
Reducing child conduct problems and promoting social skills in a middle-income country: cluster randomised controlled trial ${ }^{\dagger}$
}

\author{
Helen Baker-Henningham, Stephen Scott, Kelvyn Jones and Susan Walker
}

\section{Background}

There is an urgent need for effective, affordable interventions to prevent child mental health problems in low- and middleincome countries.

\begin{abstract}
Aims
To determine the effects of a universal pre-school-based intervention on child conduct problems and social skills at school and at home.
\end{abstract}

\section{Method}

In a cluster randomised design, 24 community pre-schools in inner-city areas of Kingston, Jamaica, were randomly assigned to receive the Incredible Years Teacher Training intervention $(n=12)$ or to a control group $(n=12)$. Three children from each class with the highest levels of teacherreported conduct problems were selected for evaluation, giving 225 children aged 3-6 years. The primary outcome was observed child behaviour at school. Secondary outcomes were child behaviour by parent and teacher report, child attendance and parents' attitude to school. The study is registered as ISRCTN35476268.

\section{Results}

Children in intervention schools showed significantly reduced conduct problems (effect size $(E S)=0.42$ ) and increased friendship skills $(E S=0.74)$ through observation, significant reductions to teacher-reported $(E S=0.47)$ and parentreported $(E S=0.22)$ behaviour difficulties and increases in teacher-reported social skills $(E S=0.59)$ and child attendance $(E S=0.30)$. Benefits to parents' attitude to school were not significant.

\section{Conclusions}

A low-cost, school-based intervention in a middle-income country substantially reduces child conduct problems and increases child social skills at home and at school.

\section{Declaration of interest}

S.S. is a trainer in the Incredible Years Parenting Programme.
Although almost $90 \%$ of the world population of children and adolescents live in low- and middle-income countries, few trials of psychosocial interventions to prevent child mental health problems have been conducted in these countries. ${ }^{1}$ Early-onset conduct problems are the most common mental health concern in childhood, affecting $5-8 \%$ of the population at the severity level for an ICD-10 diagnosis. ${ }^{2}$ Long-term outcomes are very poor, with three- to sixfold increases in the prevalence of adult criminal violence, drug misuse, school failure, teenage pregnancy and unemployment. $^{3}$ Although proven preventative interventions exist, they reach few children, even in high-income countries. This problem is amplified in low- and middle-income countries where child mental health services are extremely limited.,

Schools offer a logical setting for interventions for children, and school-based violence prevention programmes in highincome countries have shown significant reductions to children's aggressive and disruptive behaviour and increases in child competencies. Universal interventions promote the mental health of all children, avoid stigmatisation and generally attract community support. ${ }^{6}$ However, there is limited information on the effectiveness of these programmes in low- and middle-income countries where schools often have few resources and poor conditions. In Jamaica, violence among youth and adults is particularly prevalent. ${ }^{7}$ However, there are good opportunities for early intervention as $98 \%$ of 3 - to 6-year-old children attend pre-schools so there is potential for almost universal coverage. In pilot studies we implemented the Incredible Years Teacher Training programme and showed large benefits to teachers practices and to class-wide measures of child behaviour, ${ }^{8}$ and also demonstrated that the intervention was acceptable, feasible and

†See editorial, pp. 85-87, this issue. relevant. ${ }^{9}$ The aim of this study was to evaluate on a larger scale the effect of the intervention on the behaviour of high-risk children at home and at school.

\section{Method}

\section{Study design and participants}

A cluster randomised trial was conducted in the school year September 2009 to June 2010 in 24 community pre-schools in inner-city areas of Kingston, Jamaica. Over $75 \%$ of pre-school children in Jamaica attend community pre-schools, which are provided through community organisations with government oversight. Parents pay a small fee and also provide school materials such as books and pencils. Most teachers are paraprofessionals and the schools generally have poor physical conditions, including overcrowding and few teaching and learning materials. We used 'pre-school' as the unit of randomisation to prevent contamination among teachers. Inclusion criteria for pre-schools were: three to four classes of children, at least 20 children per class, situated in a specified geographical area and all teachers consented to the trial. In total, 50 pre-schools were approached and 24 meeting the inclusion criteria were recruited (Fig. 1).

Children at high risk for subsequent externalising problems were selected for evaluation. ${ }^{2}$ An interviewer-administered screening questionnaire was conducted with each teacher. Teachers rated each child on ten items from the ICD-10 Diagnostic Criteria for Research ${ }^{10}$ for conduct disorder (loses temper, back chats, disobedient/breaks rules, annoys others, blames others, easily annoyed, often angry, spiteful to others, fights or bullies and destroys property), using a four-point scale. The three children from each class with the highest scores were enrolled. 


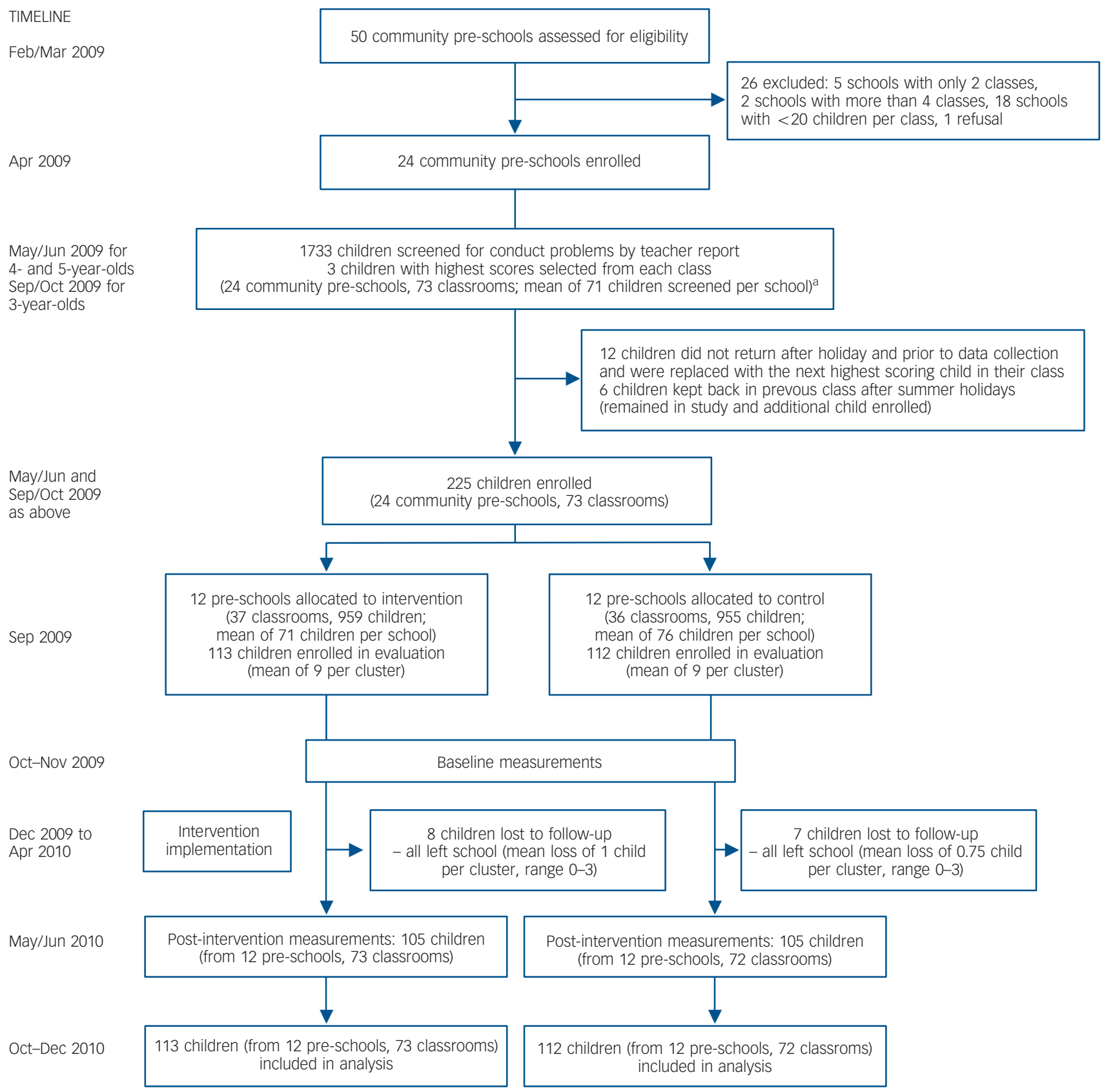

\section{Fig. 1 Trial profile.}

a. 24 high-scoring children excluded: 17 children with low attendance ( $<70 \%), 3$ siblings of enrolled child, 1 child with autism, 3 living in an institution.

Children were excluded if school attendance was $<70 \%$, they had a developmental disability, lived in an institution or were a sibling of an enrolled child. Twenty-four high-scoring children were excluded (Fig. 1) and replaced by the next highest-scoring child in their class. A total of 225 children were recruited, 113 from intervention and 112 from control schools.

The trial was approved by the University of the West Indies ethics committee. Written informed consent was obtained from all teachers and from the parents of the selected children.

The study is registered in the International Standard Randomised Controlled Trial Number Register: ISRCTN35476268.

\section{Sample size}

To detect a difference of 0.5 standard deviations with $85 \%$ power at the 0.05 level of significance, 75 participants in each group would be sufficient for a parallel group design. To take account of the cluster design, we assumed an intracluster correlation coefficient (ICC) of $0.05^{11}$ on the primary outcome of observed child behaviour. With nine children per school, the design effect was 1.4 (design effect: $1+$ (cluster size) ICC) giving a required sample size of 105 children in each group.

\section{Randomisation and masking}

Schools were randomised to intervention or control using a computer-generated simple-randomisation sequence by an independent statistician who was masked to school identity. Schools comprised separate classes of 3-, 4- and 5-year-old children, with one class per age group. One school had an additional class. Children were recruited in the summer term prior to randomisation except for the 3-year-old children entering 
school in September who were screened and recruited after randomisation by a researcher who was masked to group allocation. Parents of these children were unaware of the school's intervention status.

\section{Intervention}

\section{Teacher training intervention}

Intervention involved training all teachers and principals in the intervention schools using the Incredible Years Teacher Training Programme. ${ }^{12}$ The training methods make the intervention inherently adaptable and culturally sensitive. Methods include the use of collaborative and experiential learning, individual goal setting and self-monitoring, building teachers' self-efficacy, a focus on teachers' cognitions, behaviour and emotions, and emphasis on teachers' ability to generalise the skills learned. ${ }^{13}$ The intervention was tailored for the Jamaican pre-school context based on piloting work. ${ }^{8,9,14}$ The following adaptations were made.

(a) Supplementary video vignettes showing Jamaican classrooms were used.

(b) The intervention was delivered over 8 days rather than 5-6 days.

(c) Additional role-plays, practical activities and small group exercises were designed based on the experiences and concerns of Jamaican teachers.

(d) Additional emphasis was placed on aspects of the intervention including building positive relationships with children and parents, which is the foundation of the training programme, and being proactive in managing children's behaviour, found in piloting to be a highly valued topic, but one which teachers found challenging to implement.

(e) Handouts were revised to include examples relevant to the Jamaican context.

(f) The module on teaching social-emotional skills to children was enhanced by training teachers in specific techniques and activities to teach and reinforce child social skills.

The additional training exercises and use of Jamaican examples were aimed at increasing teachers' self-confidence and their understanding and application of the skills introduced in the programme and enhancing their ability to generalise the skills to their classroom.

Intervention school staff attended eight full-day workshops from December 2009 to April 2010. Four days were routinely held in-service training days, and teachers attended in two groups of 25-30 participants. For the remaining 4 days, teachers attended in four groups with $12-16$ teachers per group. To ensure fidelity, in-class assistance involving modelling, coaching, and support and feedback in the implementation of the strategies was provided to each teacher once a month for 4 months for $1 \mathrm{~h}$. A small amount of educational materials was provided to facilitate use of the strategies. Teachers in control schools attended the regular in-service workshops focusing on curriculum delivery provided by the Ministry of Education, and were visited twice from January to April to record child attendance and received the same educational materials.

\section{Personnel}

Workshops were conducted by H.B.H. who had attended accredited training in the Incredible Years teacher, parent and child programmes, conducted the Incredible Years Teacher Training Programme for the pilot study in Jamaica, and co-led Incredible Years teacher and parent training groups with an
Incredible Years mentor in Wales. In-class support was provided by a psychology graduate who had co-led the teacher training workshops and facilitated a series of child training workshops based on the Incredible Years child training programme in 15 Jamaican pre-school classrooms in the pilot study. She received additional training and continuing supervision from H.B.H.

\section{Monitoring of intervention implementation}

The workshop facilitator completed a training protocol and selfevaluation after each workshop and the teachers completed workshop evaluations. All content was covered and teachers rated the workshops (content, video vignettes, group leader skills and group discussion) as helpful or very helpful for all eight workshops. The strengths and needs of each teacher were documented following in-class consultations and used to inform the ongoing planning of the intervention.

\section{Measures}

The primary outcome was directly observed in-class child behaviour. Secondary outcomes were teacher and parent reports of child behaviour, child attendance and parents' attitude to school. All measures were completed at baseline (OctoberNovember 2009) and post-intervention (May-June 2010) except for parents' attitude to school, which was completed at postintervention only.

\section{Observations of child behaviour}

Within each class, three children were observed for 5 min each on a rotational basis for a total of $15 \mathrm{~min}$ each day per child over 4 days, across different times of the school day giving a total of $1 \mathrm{~h}$ of observation. Event recording was used to count aggressive/destructive behaviours (e.g. hitting, pushing, throwing objects) and friendship skills (e.g. sharing, working together) and expressed as frequency per hour. Instantaneous sampling (i.e. recording whether or not the behaviour was present at each sample point) was used to code disruptive behaviours (e.g. shouting, out of seat) at $15 \mathrm{~s}$ intervals, with a maximum possible score of 240. The aggressive/destructive and disruptive behaviours chosen were based on the Dyadic Parent-Child Interaction Coding System (DPICS $)^{15}$ and Multi-Option Observation System for Experimental Studies (MOOSES) ${ }^{16}$ behaviour categories, operationalised for the Jamaican pre-school context. All behaviours were defined in a manual. At the end of each $5 \mathrm{~min}$ observation period, observers rated the frequency of conduct problems, activity level, on-task behaviour and follows rules/ expectations of the classroom using seven-point rating scales (with behavioural descriptors on each point of the scale). Higher scores indicate higher levels of the behaviours.

\section{Teacher and parent reports of child behaviour}

For teacher-reported child behaviour, we used the Sutter-Eyberg Student Behavior Inventory (SESBI ${ }^{17}$ to measure child conduct problems, Connor's Global Index ${ }^{18}$ to measure hyperactivity and attention difficulties, the Strengths and Difficulties Questionnaire $(\mathrm{SDQ})^{19}$ to measure behaviour difficulties and prosocial skills, and the Preschool and Kindergarten Behavior Scales (PKBS): Social Skills Scale ${ }^{20}$ to measure social skills. For parent-reported child behaviour, we used the Eyberg Child Behavior Inventory (ECBI) ${ }^{21}$ to measure child conduct problems, and the $\mathrm{SDQ}^{19}$ to measure behaviour difficulties and prosocial skills. 


\section{Other outcome measures}

Child attendance was taken from school records. The parents' attitude to school was measured through a ten-item questionnaire that included items on the parents' relationship with the teacher and their opinion on teacher effectiveness and the teachers' relationship with their child (range 0-40). Higher scores represent a more positive attitude.

\section{Quality of measures and masking}

For the child observational data, intraclass correlation coefficients between the observers and trainer and between each pair of observers were calculated for $5 \mathrm{~min}$ observation periods prior to data collection at baseline and post-intervention and for $15 \%$ of observations during the study. The ICCs were: median 0.86 (range 0.74-0.96) during training and 0.83 (range 0.67-0.91) during the study (online Table DS1). All teacher and parent questionnaires were interviewer administered and inter-interviewer ICCs were $>0.95$. Internal reliabilities and test-retest over 2 weeks were adequate (online Table DS2). Measurements were conducted by researchers masked to study design, hypothesis and group allocation, who conducted equal numbers of measurements per group. Five researchers conducted child observations, three conducted teacher questionnaires and two conducted parent questionnaires. Teachers were aware of allocation status at baseline and post-intervention. To maintain masking of researchers: teachers were asked at initial contact and prior to each assessment not to reveal intervention status; observers and interviewers were not informed of the study design and were employed during the measurement phases of the study only; and intervention and control schools were provided with the same materials.

\section{Statistical analysis}

All analyses were pre-specified. The distributions of continuous dependent variables were examined for normality. ${ }^{22}$ Normality was rejected for observed aggressive/destructive behaviour, friendship skills and disruptive behaviour, and for child attendance and parent attitude to school. The three behaviour variables were $\log$ transformed, whereas child attendance and parent attitude to school were normalised by squaring. Factor analyses, with varimax rotation, were used to reduce the number of outcome variables and identify underlying constructs with separate factor analyses conducted for the observational, teacher report and parent report variables. The numbers of children scoring above the clinical cut-off for conduct problems by teacher and parent report at baseline and post-intervention was also calculated.

The effect of intervention on continuous variables was examined using multilevel multiple regression models, which are the appropriate form of analysis for a clustered trial where outcomes are observed at level 1 (children), who are taught in classes (level 2) and the intervention is at level 3 (pre-school). ${ }^{23}$ The dependent variables were the post-intervention scores for the summary variables created from the factor analyses. In all analyses, child age and gender, baseline score and intervention status were entered as fixed effects and school and classroom were entered as random effects. We analysed the binary outcomes using random-effects logistical-regression models with the same covariates. Models were estimated with Markov chain Monte-Carlo (MCMC) estimation methods, which are known to give better estimates when the number of units is relatively small. ${ }^{24}$ Analyses were conducted on an intention-to-treat basis, using the baseline scores for missing data at post-intervention. Multilevel analyses were conducted with MlwiN (version 2.10,
Centre for Multilevel Modelling, University of Bristol, UK ${ }^{25}$ for Windows.

\section{Results}

\section{Uptake of intervention}

Teachers attended a median of eight workshops (range 2-8), with $70 \%$ attending all eight and $95 \%$ attending at least six workshops; $89 \%$ of teachers received all four in-class consultations with four teachers $(11 \%)$ receiving $0-3$.

\section{Sample characteristics}

All 24 pre-schools were followed to the end of the trial (Fig. 1). Fifteen children were lost to follow-up (eight intervention and seven control) and these children did not differ from those retained.

There were no significant differences between the groups on child, family, classroom or school characteristics at baseline (Table 1).

\section{Findings}

Table 2 shows the raw scores of all outcomes by group at baseline and post-intervention; there were no significant baseline differences between the groups.

Factor analysis yielded similar results at baseline and postintervention producing five factors: observed conduct problems, observed friendship skills, teacher-reported behaviour difficulties, teacher-reported social skills and parent-reported behaviour difficulties (Table 3). Summary variables were calculated by summing the standardised scores of the variables loading on each factor (Table 3).

Intervention led to significant benefits in observed child behaviour (Table 4), with reductions in conduct problems (effect size $(\mathrm{ES})=0.42$ ) and increased friendship skills $(\mathrm{ES}=0.74)$. Significant benefits were also found for teacher-reported child behaviour difficulties $(E S=0.47)$ and social skills $(E S=0.59)$, and parent-reported child behaviour difficulties $(E S=0.22)$. There were significant benefits for child attendance $(\mathrm{ES}=0.30)$ but not for parents' attitude to school ( $E S=0.16, P=0.26$ ). A similar proportion of children from both groups were rated as being in the clinical range for conduct problems by teachers and parents at baseline (Table 5). Children in the intervention group were less likely to be rated in the clinical range by teachers at post-test and were less likely to have pervasive conduct problems (Table 5). There was no significant change in the proportion of children scoring in the clinical range by parent report.

\section{Discussion}

This study is the first in a middle-income country to show that training teachers in classroom behaviour management and social skill promotion can lead to significant and clinically important reductions in child conduct problems and increases in social skills among pre-school children with antisocial behaviour. Benefits were demonstrated by direct observation as well as by teacher and parent report; the mean effect size for child behaviour was 0.49. Meta-analyses of universal school-based violence prevention programmes have shown mean effect sizes of 0.21 for child aggressive behaviour ${ }^{26}$ and 0.24 for child social skills. ${ }^{27}$ The larger effect sizes found in this study could be because of the relatively poor initial level of training of the teachers thus widening the intervention-control gap, because we evaluated only children with high levels of conduct problems at baseline and because 


\begin{tabular}{|c|c|c|c|}
\hline & Intervention & Control & $P$ \\
\hline \multicolumn{4}{|l|}{ Child characteristics } \\
\hline$n$ & 113 & 112 & \\
\hline Child age, years: mean (s.d.) & $4.2(0.9)$ & $4.2(0.8)$ & 0.86 \\
\hline Child gender, boys: $n(\%)$ & $67(59.3)$ & $71(63.4)$ & 0.53 \\
\hline \multicolumn{4}{|l|}{ Family characteristics } \\
\hline$n$ & 113 & 112 & \\
\hline Age of caregiver, years: mean (s.d.) & $31.5(10.6)$ & $30.0(8.7)$ & 0.22 \\
\hline Number of possessions, ${ }^{a}$ mean (s.d.) & $8.9(2.4)$ & $8.9(2.6)$ & 0.98 \\
\hline Crowding, ${ }^{\text {, }}$ mean (s.d.) & $2.2(1.3)$ & $2.0(1.0)$ & 0.35 \\
\hline Mother lives with child, $n$ (\%) & $90(79.6)$ & $96(85.7)$ & 0.36 \\
\hline Father lives with child, $n(\%)$ & $47(41.6)$ & $45(40.2)$ & 0.87 \\
\hline Caregiver employed, yes: $n$ (\%) & $59(52.2)$ & $72(64.3)$ & 0.07 \\
\hline Caregiver completed high school, $n(\%)$ & $46(40.7)$ & $47(42.0)$ & 0.85 \\
\hline \multicolumn{4}{|l|}{ Classroom and teacher characteristics } \\
\hline$n$ & 37 & 36 & \\
\hline Age of teacher, years: mean (s.d.) & $38.2(10.7)$ & $42.8(9.8)$ & 0.20 \\
\hline Number of years teaching mean (s.d.) & $12.6(9.0)$ & $13.8(8.1)$ & 0.65 \\
\hline Number of years teaching at current school, mean (s.d.) & $7.9(7.1)$ & $11.4(6.1)$ & 0.06 \\
\hline Number of children in class, mean (s.d.) & $23.2(6.9)$ & $25.2(6.4)$ & 0.19 \\
\hline Trained teacher, $n$ (\%) & $4(10.8)$ & $3(8.3)$ & 0.72 \\
\hline Currently attending teacher training college, $n$ (\%) & $8(21.6)$ & $9(25.0)$ & 0.73 \\
\hline Gender of teacher, female: $n(\%)$ & $34(91.9)$ & $35(97.2)$ & 0.32 \\
\hline \multicolumn{4}{|l|}{ School characteristics } \\
\hline$n$ & 12 & 12 & \\
\hline Average school attendance in first term, mean \% (s.d.) & $80.5(6.4)$ & $77.9(7.9)$ & 0.39 \\
\hline Number of children enrolled, mean (s.d.) & $71.2(22.5)$ & $75.7(10.8)$ & 0.54 \\
\hline
\end{tabular}

\begin{tabular}{|c|c|c|c|c|}
\hline & \multicolumn{2}{|c|}{ Intervention $(n=113)$} & \multicolumn{2}{|c|}{ Control $(n=112)$} \\
\hline & Baseline & Post-intervention & Baseline & Post-intervention \\
\hline \multicolumn{5}{|c|}{ Structured observations of child behaviour, median (range) } \\
\hline Aggressive/destructive behaviour $^{a}$ & $12(0-50)$ & $9(0-50)$ & $13(0-45)$ & $13(0-49)$ \\
\hline Friendship skills ${ }^{a}$ & $4(0-29)$ & $9(0-47)$ & $5(0-38)$ & $4(0-23)$ \\
\hline Disruptive behaviour ${ }^{\mathrm{b}}$ & $32(3-89)$ & $23(2-127)$ & $32(6-98)$ & $32(3-164)$ \\
\hline \multicolumn{5}{|l|}{ Rating scales of child behaviour, ${ }^{\mathrm{C}}$ mean (s.d.) } \\
\hline Conduct problems & $2.70(0.85)$ & $2.35(0.79)$ & $2.81(0.85)$ & $2.63(0.88)$ \\
\hline Activity level & $3.32(0.73)$ & $3.27(0.50)$ & $3.19(0.67)$ & $3.32(0.52)$ \\
\hline Follows rules and expectations & $4.75(0.72)$ & $5.09(0.72)$ & $4.63(0.67)$ & $4.79(0.68)$ \\
\hline On-task behaviour & $4.95(0.87)$ & $5.52(0.70)$ & $4.85(0.84)$ & $5.14(0.81)$ \\
\hline \multicolumn{5}{|l|}{ Teacher reports of child behaviour, mean (s.d.) } \\
\hline Conduct problems (SESBI) & $154.29(44.38)$ & $123.99(47.13)$ & $152.45(31.96)$ & $145.07(38.59)$ \\
\hline ADHD symptoms (Connor's Global Index) & $16.63(6.05)$ & $12.44(6.68)$ & $16.74(5.90)$ & $15.72(6.36)$ \\
\hline Child social skills (PKBS) & $67.00(13.86)$ & $77.22(14.25)$ & $70.60(12.58)$ & $73.04(11.41)$ \\
\hline Total behaviour difficulties (SDQ) & $17.27(6.51)$ & $14.73(6.93)$ & $16.54(5.03)$ & $16.48(5.69)$ \\
\hline Prosocial skills (SDQ) & $5.30(2.31)$ & $7.09(2.23)$ & $5.49(2.32)$ & $5.87(1.90)$ \\
\hline \multicolumn{5}{|l|}{ Parent reports of child behaviour, mean (s.d.) } \\
\hline Conduct problems (ECBI) & $120.05(22.66)$ & $121.67(23.91)$ & $119.83(24.26)$ & $127.22(23.97)$ \\
\hline Total behaviour difficulties (SDQ) & $15.73(5.67)$ & $16.33(5.61)$ & $15.54(5.17)$ & $16.34(5.06)$ \\
\hline Prosocial skills (SDQ) & $7.33(2.23)$ & $7.83(2.20)$ & $7.82(1.87)$ & $7.65(2.10)$ \\
\hline \multicolumn{5}{|c|}{ Child attendance and parent involvement in school, median (range) } \\
\hline School attendance & $92(31-100)$ & $90(48-100)$ & $91(45-100)$ & $88(30-100)$ \\
\hline Parents' attitude to school $^{d}$ & - & $28.0(5-39)$ & - & $27.5(12-37)$ \\
\hline \multicolumn{5}{|c|}{$\begin{array}{l}\text { SESBI, Sutter-Eyberg School Behavior Inventory; ADHD, attention-deficit hyperactivity disorder; PKBS, Preschool and Kindergarten Behavior Scales; SDQ, Strengths and Difficulties } \\
\text { Questionnaire; ECBI, Eyberg Child Behavior Inventory. } \\
\text { a. Event sampling. } \\
\text { b. Instantaneous sampling at } 15 \text { s intervals (maximum possible score } 240 \text { ). } \\
\text { c. Mean of } 12 \text { ratings conducted every } 5 \text { min on a scale } 0-7 \text {, where } 0 \text { is low and } 7 \text { is high. } \\
\text { d. } n=210 \text { (105 intervention, } 105 \text { control). }\end{array}$} \\
\hline
\end{tabular}

the intervention was implemented with high levels of fidelity. All these factors have been shown to predict greater effectiveness. ${ }^{26,27}$

Significantly more children attending intervention schools moved into the non-clinical range on teacher-reported conduct problems than in control schools, although the difference by parent report was not significant. Intervention also reduced the proportion of children with pervasive conduct problems who were at highest risk for long-term negative outcomes. ${ }^{2}$ Although the 
Table 3 Factor analyses of observations of child behaviour and teacher and parent reports of child behaviour at baseline and post-intervention $^{\mathrm{a}}$

\begin{tabular}{|c|c|c|c|c|}
\hline & \multicolumn{2}{|c|}{ Baseline } & \multicolumn{2}{|c|}{ Post-intervention } \\
\hline & Factor 1 & Factor 2 & Factor 1 & Factor 2 \\
\hline \multicolumn{5}{|l|}{ Child observations $^{b}$} \\
\hline Follows rules and expectations & -0.92 & & -0.93 & \\
\hline Conduct problems & 0.83 & & 0.81 & \\
\hline Activity level & 0.79 & & 0.79 & \\
\hline Aggressive/destructive behaviour & 0.78 & & 0.79 & \\
\hline On-task behaviour & -0.68 & $0.43^{\mathrm{e}}$ & -0.71 & \\
\hline Disruptive behaviour & 0.66 & & 0.79 & \\
\hline Friendship skills & & 0.86 & & 0.96 \\
\hline Variance explained, \% & 52.42 & 16.35 & 55.59 & 15.59 \\
\hline \multicolumn{5}{|l|}{ Teacher report $^{\mathrm{C}}$} \\
\hline ADHD symptoms (Connor's Global Index) & 0.92 & & 0.91 & \\
\hline Conduct problems (SESBI frequency scale) & 0.90 & & 0.89 & \\
\hline Total behaviour difficulties (SDQ) & 0.79 & $-0.48^{\mathrm{e}}$ & 0.87 & \\
\hline Prosocial skills (SDQ) & & 0.93 & & 0.94 \\
\hline Social skills (PKBS) & & 0.85 & $-0.43^{\mathrm{e}}$ & 0.83 \\
\hline Variance explained, \% & 48.01 & 37.37 & 51.68 & 35.93 \\
\hline \multicolumn{5}{|l|}{ Parent report $^{\mathrm{d}}$} \\
\hline Conduct problems (ECBI) & 0.84 & & 0.87 & \\
\hline Total behaviour difficulties (SDQ) & 0.83 & & 0.86 & \\
\hline Prosocial skills (SDQ) & -0.67 & & -0.62 & \\
\hline Variance explained, \% & 61.94 & & 62.61 & \\
\hline \multicolumn{5}{|c|}{ 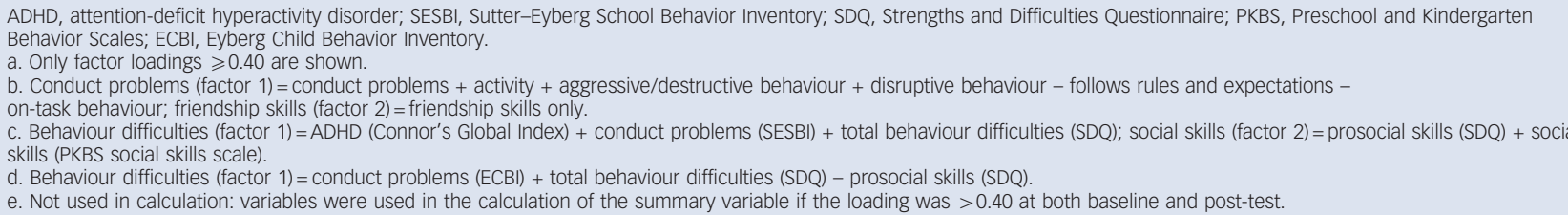 } \\
\hline
\end{tabular}

\begin{tabular}{|c|c|c|c|c|}
\hline Measure & $\begin{array}{l}\text { Regression coefficient } \\
\qquad \text { B }(95 \% \mathrm{Cl})\end{array}$ & $\begin{array}{l}\text { Intracluster correlation } \\
\text { coefficient }\end{array}$ & $\begin{array}{l}\text { Effect size }^{b} \\
(95 \% \mathrm{Cl})\end{array}$ & $P$ \\
\hline \multicolumn{5}{|l|}{ Observations of child behaviour } \\
\hline Conduct problems ${ }^{c}$ & $-1.95(-3.33$ to -0.57$)$ & 0.05 & 0.42 (0.12 to 0.71$)$ & 0.006 \\
\hline Friendship skills ${ }^{c}$ & 0.74 (0.41 to 1.40$)$ & 0.10 & 0.74 (0.41 to 1.40$)$ & $<0.0001$ \\
\hline \multicolumn{5}{|c|}{ Teacher reports of child behaviour } \\
\hline Behaviour difficulties $^{c}$ & $-1.29(-2.09$ to -0.48$)$ & 0.06 & $0.47(0.18$ to 0.76$)$ & 0.001 \\
\hline Social skills ${ }^{c}$ & 1.09 (0.64 to 1.54$)$ & 0.00 & 0.59 (0.35 to 0.84$)$ & $<0.0001$ \\
\hline \multicolumn{5}{|c|}{ Parent reports of child behaviour } \\
\hline Behaviour difficulties $^{\mathrm{C}}$ & $-0.52(-0.98$ to -0.06$)$ & 0.00 & 0.22 (0.03 to 0.42$)$ & 0.03 \\
\hline Child attendance $^{d}$ & 586.96 (102.79 to 1071.13$)$ & 0.02 & 0.30 (0.05 to 0.55$)$ & 0.02 \\
\hline Parents' attitude to school $^{d}$ & $42.31(-31.59$ to 116.21$)$ & 0.00 & $0.16(-0.12$ to 0.43$)$ & 0.26 \\
\hline \multicolumn{5}{|c|}{$\begin{array}{l}\text { a. Analysis adjusting for baseline score, child age and gender as fixed effects and school and classroom as random effects. Intervention group }=1 \text {, control group }=0 \text {. } \\
\text { b. Effect size }=\text { regression coefficient/pooled standard deviation at baseline. } \\
\text { c. Sum of standardised scores of variables loading on each factor (see Table } 3 \text { for details). } \\
\text { d. Transformed scores (square) used in the analyses. }\end{array}$} \\
\hline
\end{tabular}

\begin{tabular}{|c|c|c|c|c|c|c|}
\hline & \multicolumn{2}{|c|}{ Intervention, $n(\%)(n=113)$} & \multicolumn{2}{|c|}{ Control, $n(\%)(n=112)$} & \multirow[b]{2}{*}{$\begin{array}{c}\text { Adjusted } \\
\text { OR (95\% Cl) }\end{array}$} & \multirow[b]{2}{*}{$P$} \\
\hline & Baseline & $\begin{array}{c}\text { Post- } \\
\text { intervention }\end{array}$ & Baseline & $\begin{array}{c}\text { Post- } \\
\text { intervention }\end{array}$ & & \\
\hline Clinical range for conduct problems by teacher report ${ }^{\mathrm{b}}$ & $60(53.1)$ & $30(26.5)$ & $63(56.3)$ & $50(44.6)$ & $0.31(0.11-0.92)$ & 0.02 \\
\hline Clinical range for conduct problems by parent report ${ }^{\mathrm{C}}$ & $42(37.2)$ & $42(37.2)$ & 35 (31.3) & $49(43.8)$ & $0.56(0.27-1.16)$ & 0.11 \\
\hline Clinical range for conduct problems at school and at home ${ }^{d}$ & $25(22.1)$ & $9(8.0)$ & $20(17.9)$ & $23(20.5)$ & $0.24(0.08-0.73)$ & 0.01 \\
\hline
\end{tabular}


cut-offs for clinical conduct problems have not been validated for Jamaica, the cut-offs likely identify children at elevated risk of continuing conduct problems.

The intervention focused on training teachers and it was encouraging that small benefits were also found for parent reports of their child's behaviour difficulties. Evidence of benefits from classroom-based interventions for child behaviour at home are inconsistent, ${ }^{28-30}$ and for children with elevated conduct problems at home, adding a parenting component may be necessary. There were no significant benefits for parents' attitude to school; however, attitudes were generally positive in this population. The intervention benefited child attendance, indicating that parents sent their children to school more regularly. School-based violence prevention programmes have been shown to reduce school drop-out and truancy in older children. ${ }^{31}$

\section{Meaning and implications of study}

The Incredible Years Parenting Programme has been shown to be culturally transferable across ethnic groups in the USA, ${ }^{32}$ but to our knowledge this is the first trial of an Incredible Years programme in a low- or middle-income country. The community pre-schools in this study had high child-staff ratios, few resources and poor physical conditions including overcrowding and high noise levels. Most teachers were paraprofessionals without formal teacher training and schools were situated in disadvantaged, inner-city communities with high levels of community violence. ${ }^{33}$ Uptake by teachers was high and the benefits to child behaviour substantial, demonstrating that with careful piloting and adaptation, and attention to fidelity to the original model, this programme can be effective in a middle-income country setting.

The evidence base for psychosocial interventions to prevent behaviour problems in low- and middle-income countries is extremely limited. ${ }^{1,4,5}$ The finding that teacher training leads to widespread benefits in child behaviour is extremely important for child mental health prevention and promotion in low- and middle-income countries where services are few; it is also relevant for high-income countries. The intervention is integrated into existing services, and is relatively low cost, requiring few specialist resources. In addition, teachers can reach a number of high-risk children and can continue benefiting new cohorts of children over time. As the intervention is integrated into the pre-school system, this should be a cost-effective approach and has potential for expansion and sustainability.

\section{Strengths and weaknesses}

The trial had high response and follow-up rates, assessments were conducted by trained researchers masked to study design, hypothesis and group allocation, and analysis was by intention to treat. The primary outcome involved gold-standard direct observations of child behaviour in school. Teachers were aware of group allocation and it is possible that intervention teachers rated children more favourably post-intervention. However, effect sizes by teacher report were similar to those by independent observations. The control schools did not receive an alternate intervention and hence the benefits may be as a result of the additional attention received by intervention schools. However, teachers in control schools attended their regular training workshops hosted through the Ministry of Education and similar materials were provided to all schools. Furthermore, high-quality intervention implementation has been shown to be essential for the effectiveness of school-based violence prevention programmes. ${ }^{26}$ Although cluster randomised trials are susceptible to bias, there were no significant differences between the groups at baseline. Contamination between groups was minimised through the cluster design. Approximately $23 \%$ of teachers in both intervention and control schools were attending teacher training colleges where some sharing of strategies may have occurred. If this led to implementation of strategies by some teachers in control schools, this would reduce the size of the benefits detected. There were exclusions to participation at the level of the school and the child that may limit the generalisability of the results. Schools with less than 20 children per class were excluded to maximise the likelihood that children with the highest scores on the conduct disorder screen had behaviour problems; we anticipate that the intervention would benefit antisocial children attending schools with smaller class sizes. We excluded schools with fewer than three or more than four classes. However, as the intervention is provided for all class teachers, we would hypothesise that children attending smaller and larger schools would also benefit. Children with low attendance were excluded to ensure timely data collection; it is likely poor attendance would also reduce the benefits of intervention. The benefits reported are post-intervention only and we do not know whether these benefits will be sustained when children transition into new classrooms or schools with untrained teachers.

\section{Questions and future research}

The workshops comprised new concepts and skills for the teachers that were modelled and rehearsed. Teachers also received in-class consultations to assist them in the application of these skills. The study design does not allow us to identify the relative importance of these components, which is important for planning wider dissemination of the programme.

Although we implemented a universal intervention, only children with elevated levels of conduct problems at school were evaluated, and hence we do not know whether the intervention benefited children with low-to-moderate levels of conduct problems. It is possible that the intervention benefited the mental health of all children. Furthermore, previous studies have found benefits to academic achievement from school-based violence prevention $^{26}$ and social skills training programmes ${ }^{27}$ and school readiness should be measured in future studies. It will also be important to determine whether the benefits to child behaviour are sustained, especially as children transition to primary school.

\footnotetext{
Helen Baker-Henningham, PhD, Tropical Medicine Research Institute, University of the West Indies, Kingston, Jamaica; Stephen Scott, FRCPsych, Department of Child the West Indies, Kingston, Jamaica; Stephen Scott, FRCPSych, Department of
and Adolescent Psychiatry, Institute of Psychiatry, King's College London, and National Academy for Parenting Research, London, UK; Kelvyn Jones, PhD, Centre for Multilevel Modelling, University of Bristol, Bristol, UK; Susan Walker, PhD, Tropical Medicine Research Institute, University of the West Indies, Kingston, Jamaica

Correspondence: Helen Baker-Henningham, Tropical Medicine Research Institute, University of the West Indies, Mona, Kingston, Jamaica. Email: helen.henningham@uwimona.edu.jm

First received 27 May 2011, final revision 18 Jan 2012, accepted 18 Jan 2012
}

\section{Funding}

The project was funded by a Wellcome Trust Research Training Fellowship to H.B.H. [080534/Z/06/Z].

\section{Acknowledgements}

We thank Professor Judy Hutchings for training H.B.H. through a 3-month placement at the Incredible Years Wales Centre. We thank Yakeisha Townsend for assisting with the intervention, the staff, parents and children of the 24 community pre-schools for their participation and the research assistants for data collection. 


\section{References}

1 Kieling C, Baker-Henningham H, Belfer M, Conti G, Ertem I, Omigbodun O, et al. Global child and adolescent mental health: evidence for action. Lancet 2011; 378: 1515-25.

2 Moffitt T, Scott S. Conduct disorders in childhood and adolescence. In Rutter's Child and Adolescent Psychiatry (5th edn) (ed M Rutter, D Bishop, D Pine, S Scott, J Stevenson, E Taylor, et al): 543-64. Blackwell Publishing, 2008.

3 Fergusson DM, Horwood L, Ridder EM. Show me the child at seven: the consequences of conduct problems in childhood for psychosocial functioning in adulthood. J Child Psychol Psychiatry 2005; 46: 837-49.

4 Patel V, Aroya R, Chatterjee S, Chisholm D, Cohen A, De Silva M, et al. Global Mental Health 3 - treatment and prevention of mental disorders in lowincome and middle-income countries. Lancet 2007; 370: 991-1005.

5 Belfer ML. Child and adolescent mental disorders: the magnitude of the problem across the globe. J Child Psychol Psychiatry 2008; 49: 226-36.

6 Offord DR. Selection of levels of prevention. Addict Behav 2000; 25: 833-42.

7 Le Franc E, Samms-Vaughan M, Hambleton I, Fox K, Brown D. Interpersonal violence in three Caribbean countries: Barbados, Jamaica, and Trinidad and Tobago. Rev Panam Salud Publica 2008; 24: 409-21.

8 Baker-Henningham $\mathrm{H}$, Walker S, Powell C, Gardner JM. A pilot study of the Incredible Years Teacher Training programme and a curriculum unit on social and emotional skills in community pre-schools in Jamaica. Child Care Health Dev 2009; 35: 624-31.

9 Baker-Henningham $\mathrm{H}$, Walker S. A qualitative study of teacher's perceptions of an intervention to prevent conduct problems in Jamaican pre-schools. Child Care Health Dev 2009; 35: 632-42.

10 World Health Organization. The ICD-10 Classification of Mental and Behavioural Disorders. Diagnostic Criteria for Research. WHO, 1993.

11 Campbell M, Grimshaw J, Steen N. Sample size calcuation for cluster randomised trials. Changing professional practice in Europe group. $J$ Health Serv Res Policy 2000; 5: 12-6.

12 Webster-Stratton C. The Incredible Years Training Series. Office of Juvenile Justice and Delinquency Prevention, Juvenile Justice Bulletin, 2000.

13 Webster-Stratton C, Reinke WM, Herman KC. The Incredible Years Teacher Training: The Methods and Principles that Support Adaptation and Dissemination with High Fidelity. Incredible Years Corporation, no date (http://www.incredibleyears.com/Library/items/the-incredible-years-teachertraining-methods_11.pdf)

14 Baker-Henningham $\mathrm{H}$. Transporting evidence-based interventions across cultures: using focus groups with teachers and parents of preschool children to inform the implementation of the Incredible Years Teacher Training Programme in Jamaica. Child Care Health Dev 2011; 37: 649-61.

15 Eyberg S, Robinson EA. Dyadic Parent-Child Interaction Coding System. Parenting Clinic, University of Washington, 1981.

16 Tapp J, Wehby JH, Ellis D. A multiple observation system for experimental studies: MOOSES. Behav Res Methods Instrum Comput 1995; 27: 25-31.
17 Rayfield A, Eyberg SM, Foote R. Revision of the Sutter-Eyberg Student Behavior Inventory: teacher ratings of conduct problem behavior. Educ Psychol Meas 1998; 58: 88-98.

18 Kollins SH, Epstein JN, Conners KC. Conners' Rating Scales - Revised. In The Use of Psychological Testing for Treatment Planning and Outcomes Assessment (3rd edn) (ed. ME Maruish): 215-32. Lawrence Erlbaum Associates, 2004

19 Goodman R. The extended version of the Strengths and Difficulties Questionnaire as a guide to child psychiatric caseness and consequent burden. J Child Psychol Psychiatry 1999; 40: 791-9.

20 Merrell KW. Assessment of social skills and behavior problems in early childhood: the Preschool and Kindergarten Behavior Scales. J Early Interv 1996; 20: 132-45.

21 Eyberg SM, Ross AW. Assessment of child behavior problems: the validation of a new inventory. J Clin Child Adolesc Psychol 1978; 7: 113-6.

22 Shaprio SS, Wilk MB. An analysis of variance test for normality (complete samples). Biometrika 1965; 52: 591-611.

23 Hayes HJ, Moulton LH. Cluster Randomised Trials. CRC, 2009.

24 Browne WJ. MCMC Estimation in MLWin Version 2.13. Centre for Multileve Modelling, University of Bristol, 2009 (http://seis.bris.ac.uk/ frwjb/esrc/ mcmc.pdf).

25 Rasbash J, Charlton C, Browne WJ, Healy M, Cameron B. A User's Guide to MLwiN V2.1. Centre for Multilevel Modelling, University of Bristol, 2009 (http://www.bristol.ac.uk/cmm/software/mlwin/download/mlwin-userman-09.pdf).

26 Wilson SJ, Lipsey MW. School-based interventions for aggressive and disruptive behavior - update of a meta-analysis. Am J Prev Med 2007; 33: S130-43.

27 Durlak JA, Weissberg RP, Dymnicki AB, Taylor RD, Schellinger KB. The impact of enhancing students' social and emotional learning: a meta-analysis of school-based universal interventions. Child Dev 2011; 82: 405-32.

28 Grossman DC, Neckerman HJ, Koepsell TD, Liu PY, Asher KN, Beland K, et al. Effectiveness of a violence prevention curriculum among children in elementary school. A randomized controlled trial. JAMA 1997; 277: 1605-11.

29 lalongo NS, Werthamer L, Kellam SG, Brown CH, Wang S, Lin Y. Proximal impact of two first-grade preventive interventions on the early risk behaviors for later substance abuse, depression, and antisocial behavior. Am J Community Psychol 1999; 27: 599-641.

30 Webster-Stratton C, Jamila RM, Stoolmiller M. Preventing conduct problems and improving school readiness: evaluation of the Incredible Years Teacher and Child Training Programs in high-risk schools. J Child Psychol Psychiatry 2008; 49: 471-88.

31 Wilson DB, Gottfredson DC, Najaka SS. School-based prevention of problem behaviors: a meta-analysis. J Quant Criminol 2001; 17: 247-72.

32 Reid MJ, Webster-Stratton C, Beauchaine TP. Parent training in head start: a comparison of program response among African American, Asian American, Caucasian, and Hispanic mothers. Prev Sci 2001; 2: 209-27.

33 Baker-Henningham H, Meeks-Gardner J, Chang S, Walker S. Experiences of violence and deficits in academic achievement among urban primary school children in Jamaica. Child Abuse Negl 2009; 33: 296-306.

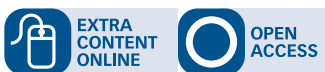

